\title{
The Intelligent Egg, and How It Got That Way: from Genes to Genius in a Few Easy Lessons
}

\author{
Kenneth M. Weiss
}

Published online: 10 May 2012

(C) Springer Science+Business Media, LLC 2012

\begin{abstract}
A seed has no flowers or leaves, and an egg no fingers or lungs. Yet plants and animals not only have these things but they resemble their parents in detail throughout their bodies. Something is inherited, but what is it? Life is based on the activities of cells. An organism has large numbers of them-a human has trillions! Cells live as separate units, which enables them each to do its own thing within its particular organ, but to be an organism they must work together. A cell can only detect its immediate local environment, but that includes various kinds of signals or information from nearby or far away within the body-or even from the external environment. It is by being local but responding globally in this way that an egg becomes an organism, an organism manages its way through life, and organisms make up species and ecosystems that interact with each other. The evolution of these abilities has produced the glorious array of living forms that populate the world. In these ways, an egg may have no thoughts but is a highly intelligent being.
\end{abstract}

Keywords Developmental genetics · Genome evolution . Genetics $\cdot$ Development $\cdot$ Signaling $\cdot$ Cooperation

One of the most fascinating facts of life is that even complex organisms like humans begin as single cells. We're each a continuation of the lives of our parents, constricted through a single cell, the fertilized egg. That cell is able to divide into a family of many billions of descendant cells, which

\section{K. M. Weiss $(\bowtie)$}

Department of Anthropology, Penn State University, 409 Carpenter Building,

University Park, PA 16802, USA

e-mail: kenweiss@psu.edu end up doing very different things but work together as a single unit with its common origin in the egg.

These facts lead to the fundamental, totally captivating question: How does the egg do this?

\section{Some Historical Ideas About What Is Inherited}

People have probably wondered where new animals or plants came from since they wondered about anything. We know most about this from the first recorded writings about the subject, which in the Western tradition goes back to classical times. Over the 3,000 or so years since those times, several ideas have been put forward.

Once it was realized that both parents contribute to new organisms, it was debated whether the male or female was most responsible. This is oversimplified, but there have been two major ideas. One is that, like Russian dolls, gonads might contain endlessly nested, ever-smaller miniatures of future individuals. This was called preformation, and if true it meant that after fertilization's stimulating effect, all that was needed was for the miniature organism to grow. A famous drawing from 1695 showed an example of such a homunculus nested within a sperm cell (Fig. 1). Plants could have similarly miniature individuals that first became visible when they sprouted.

Others suggested that life might arise spontaneously, out of the right ingredients in the soil, which came together to form the individuals. For example, in "On the generation of animals," Aristotle speculated along these lines. Spontaneous generation was seriously questioned in an experimental way by Spallanzani in the 1700s (Spallanzani 1784), who showed that the famous example of maggots arising from dead meat was really the result of eggs that had been laid by flies in the meat. If the meat was covered with gauze that 


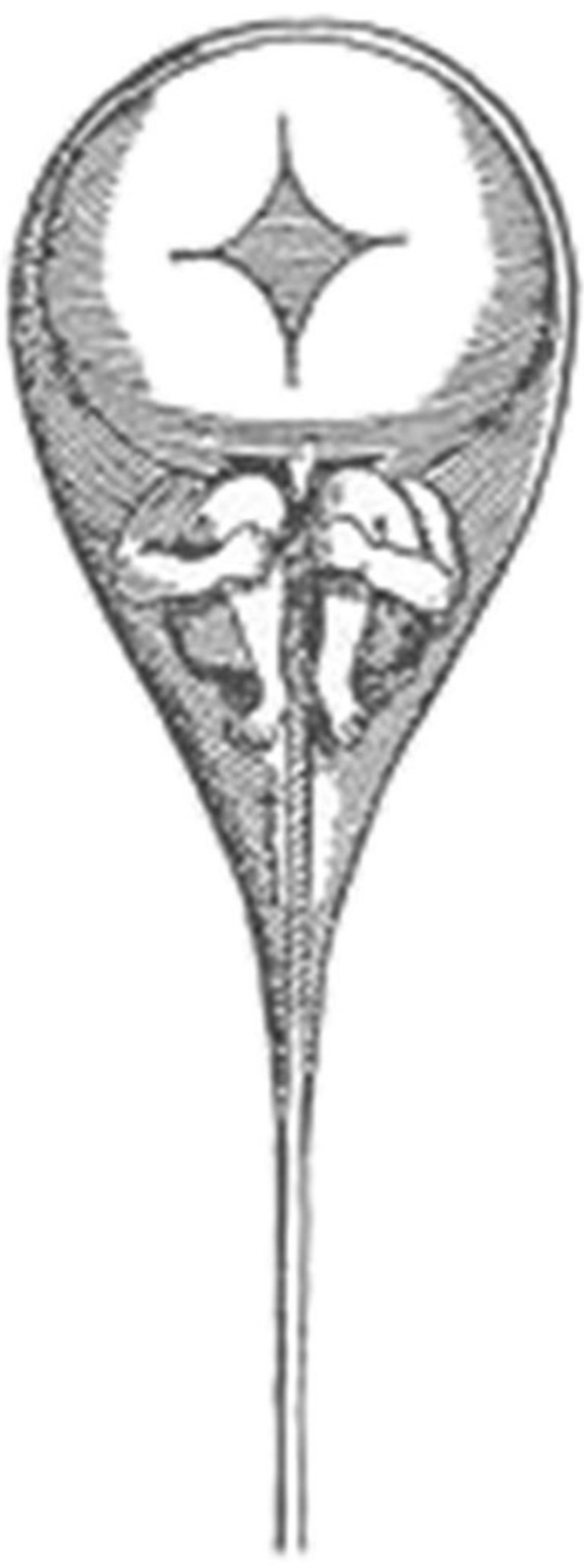

Fig. 1 Homunculus. From N. Hartsoecker, 1695

kept the flies away, no maggots appeared. Figure 2 shows my own repetition of these classical experiments (Weiss 2004). Spallanzani also showed that fertilization was necessary for embryos to develop. There is no spontaneous generation of organisms.

In terms of more specific ideas, about $400 \mathrm{BC}$, Hippocrates suggested that the parts of individuals were comprised of some sort of miniature representations, which were shed into the gonads to be later transmitted to the next generation, which used them simply to reconstruct their own tissues and organs (Hippocrates $450 \mathrm{BCE}$ ). This idea was expressed in
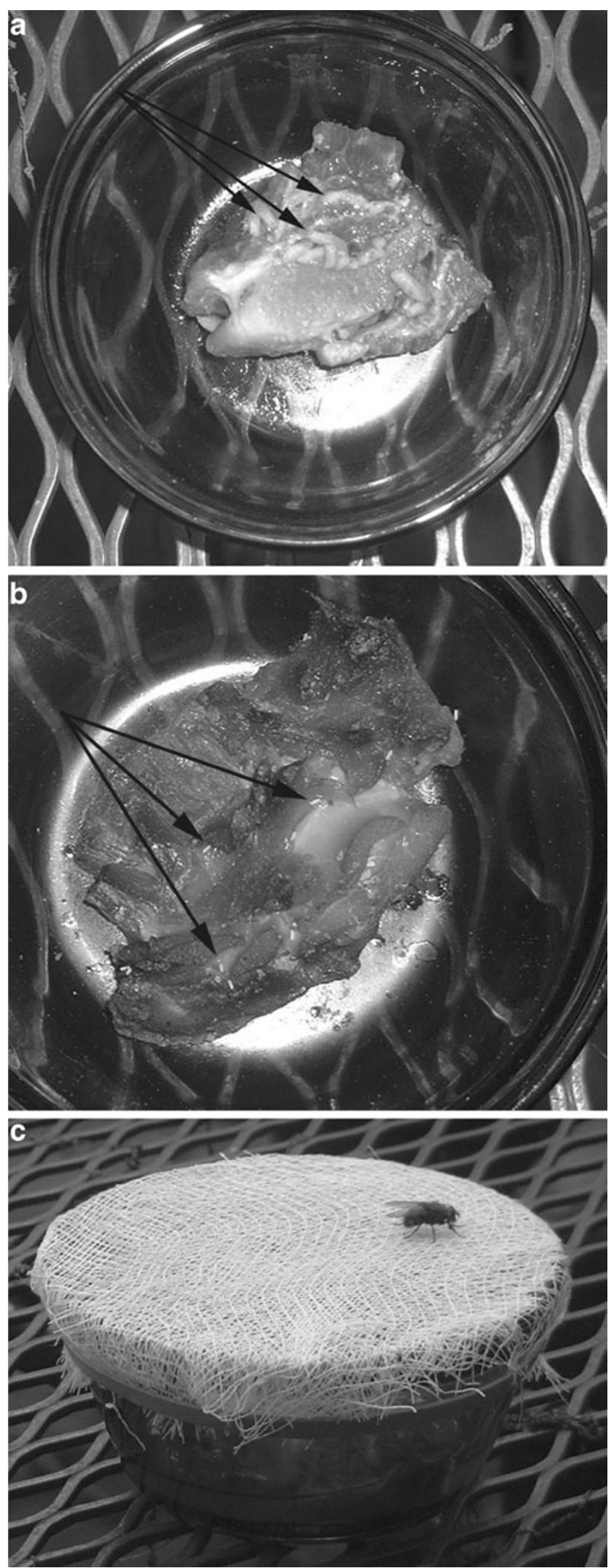

Fig. 2 Meaty maggots. a Maggots emerge from dead meat (arrows). b It was later discovered that these arise only from fly eggs (arrows). c With a gauze barrier, no maggots, but a hungry, frustrated fly. Experiment and photos by the author (Weiss 2004) 
many ways but in the history of science, perhaps most notably by Jean Lamarck in 1809 , who suggested that these miniatures were modified by the way the future parents lived their lives, and the modified miniatures were then transmitted to their offspring. This is known as "the inheritance of acquired characteristics," and Lamarck built a whole theory of evolution around it to explain the origin of the traits of different species that adapted, or fitted, the species to their particular circumstances of life.

Lamarck's idea was that these miniature factors were modified by the actions of the individual during its lifetime. The modified versions were transmitted to the next generation. Over time, if each generation of individuals acted in similar ways-like running, taking to the water, or in other ways taking advantage of opportunities presented by the environment, the species would gradually adapt to the new, modified behavior. Slowly, major change in form and function would take place.

Charles Darwin's theory of evolution was in one sense formally very different. As we now think of it, inherited units (that we now call "genes") are modified by random changes (we now call them "mutations"), that occur regardless of what effect (if any) they might have on the organism that bears them. Those changes that happen by chance to make the organism suited to its environment and needs for life at that particular time and place enable it to successfully reproduce - meaning to transmit the change to its offspringmore frequently than organisms who don't have the advantageous change. Harmful changes disappear because their bearers don't reproduce as well. It was slow, because most changes, unless very slight, would be harmful, but there had been plenty of time on earth for the diversity of modern forms to have evolved by building up countless individually small genetic changes.

Darwin's is a modern view of the basic aspects of adaptive evolution. But he himself had no idea about exactly what was inherited, and in a rather confused way he also suggested little miniatures that are modified by the organism's behavior and circumstances - much as had Lamarck and other thinkers back to Hippocrates. It was certainly a sensible way to think before more was known about the contents of seeds in animals and plants. Darwin mixed "Lamarckian" and what was now know was his more accurate model of evolutionary change based on random mutation, stressing that he thought the latter probably were more important. Still, what was inherited was, in his guesses, some sort of miniature representation of the individual's traits.

I'm oversimplifying for brevity, but whatever these miniature items were, they were viewed as deterministic and deterministically inherited. That means that if you possessed them, the miniatures were destined to be transmitted, and that if inherited, they made themselves manifest. How this worked was not known, because understanding things at what we now would say is the molecular level just did not yet exist. In fact, Darwin tried hard to explain how his theory could account for various observations such as that some traits skip generations (Darwin 1900).

Meanwhile, quietly working away in his monastery garden in Moravia, Gregor Mendel was following a different kind of abstract molecular theory of inheritance. To him, too, some sort of invisible miniature "elements" were transmitted by parents, which somehow determined the traits in domestic pea plants that he chose to look at. Each parent contained one or both of two existing types of such elements but transmitted only one of these to each offspring. Here, basically unlike the prior classical ideas, Mendel showed that the transmission of these factors was not deterministic, but probabilistic: In a parent carrying the two different elements related to a trait would have a 50-50 chance that a given of them would be transmitted in each particular instance. We cannot know, in any specific case, what will happen, only that for each trait, over many offspring, about half would have inherited the one, and the other half the other, of the given parent's elements.

Mendel worked with plants, and he knew that not every trait seemed to behave in this way, but it was later shown that similar inheritance patterns also occurred in animals. Again, it was not known what the elements were, but they were in some sense causal: a fertilized plant or animal seed developed from some state too small to understand with the technologies then available, into the organized structure of the organism. It's one thing to describe how inheritance happened, but what was the generative mechanism?

\section{How Genetic Information Works}

The inherited causal elements were given the name "genes" early in the twentieth century, but it took many decades to understand where in the cell these causal elements are located and what their nature is. A fundamental finding was that genes are individual molecules rather than readyformed miniature parts of organs. Individual genes were identified because their variation was associated with variation in some trait-much of the work was done in fruit flies, which are easy, cheap, and fast to manage in the laboratory, and had many easily recognized variable traits. It was shown that these genes were segments strung along super-size molecules called "chromosomes," located in the nucleus of cells.

The chromosomes are long molecules of DNA (deoxyribonucleic acid), and DNA is made up of four different kinds of units, called nucleotides, and denoted A, C, G, and $\mathrm{T}$ (derived from their chemical names). These are strung together in a chain to make up a chromosome. Each species has a characteristic number of chromosomes, and that set is known as the organism's "genome." And with some minor 
exceptions, each cell in an organism contains two copies of its genome, one inherited from each parent. When cells divide into two "daughter" cells, both copies of the genome are themselves copied, and one set is transmitted to each daughter cell.

By the middle of the century, detailed analysis of this peculiar kind of very large molecule had revealed that individual genes consisted of sections of this string. And this fact led to an understanding of the basic functional nature of genes: as expressed in terms appropriate to our computer age, these molecules carry information.

The first important point is that the length of the chromosome is not constrained chemically and can be hundreds of millions of nucleotides long. Secondly, the order of the nucleotides is also not constrained. What this means is that regions, or substrings, have functions that depend on the order of their nucleotides. From mushrooms to mankind, the same system works - because it all ultimately descended from ancient common ancestry in the history of life, and because the flexibility of nucleotide order allows for information to be carried that differs from species to species throughout the living world.

This works for two major reasons. First, is that the order of nucleotides along chromosomes provides a code that is used to assemble strings of other units, called amino acids. Strings of amino acids are known as proteins, and once they are assembled, they fold up upon themselves (for chemical reasons), and their folded shape determines what other molecules, including other proteins, they will interact withbasically, that they will stick to, one perhaps altering the other in the process. Much of what makes life is the interaction of many different types of proteins within cells and on the cells' surfaces. It is the particular set of elements, including proteins, that is in or on a cell that determines what kind of cell it will be: kidney or skin, flower or leaf, insect wing or leg, animal brain or bone, or a humble bacterium or fungus.

The protein-coding part of DNA is copied, or transcribed into an intermediate molecule called RNA that has the same sequence as that part of the DNA, but in the cell is grabbed by specific organelles called "ribosomes," which translate the code by assembling the code-specified amino acids, one by one, in the same order as the nucleotide code copied from DNA, into the protein being specified. The genome of each species contains the code for all of the proteins - usually numbering in the tens of thousands - which that species needs to make.

This leaves an obvious question unanswered. What makes an organism like a tree, snail, bird, or human is that we are differentiated into many different structures and organs. For example, we have lungs, brains, fingers, and stomachs. So if each cell contains the very same genome for its species, what can this have to do with its differentiated structure that makes the species what it is? The answer is that although each cell inherits the entire genome, what makes it have its specific traits is that it only uses some of its genes, while the other genes remain silent - they are not used to code for their respective protein in that cell. And this points to the second major function of DNA. Short strings of nucleotides called "regulatory elements" are used not to code for protein but to control whether a nearby protein-coding gene will be used in a given cell. These regulatory sequences in DNA are chemically recognized by specific proteins called "transcription factors" (TFs) that the cell has already produced (being coded by genes somewhere else in the genome). The TF molecule physically recognizes the regulatory element and grabs on to it. This binding event (more accurately, similar events by multiple proteins attaching to regulatory elements and to each other) then causes a nearby gene to be transcribed into RNA, and hence translated into protein, and hence used by the cell to determine the cell's particular nature.

We have one more piece of the differentiation puzzle to describe in order to understand the intelligence of the egg, or any other cell for that matter. If a cell's nature is determined largely by the set of its genes that it is using, what determines that? The answer, in brief, is signaling, or the transfer of information among cells. Among the proteins that a cell makes, besides various TFs, are additional sets of proteins called "signal molecules" and "signal receptors." Signal molecules are secreted from the cell, where they can drift or be carried in the circulation to other places in the body. Signal receptors are molecules that can detect and respond to signal molecules, binding with them much as a key fits into a lock. When that happens, it triggers a chain of interactions inside the cell that causes specific TFs to be activated and in turn to cause specific genes to be expressed. Signals can also come from other sources such as environmental sensory input or dietary elements. From the time of fertilization onward, the development of an animal or plant embryo is a cascading sequence of changing cell differentiation, based on this kind of signaling.

What we now know is that it's the specific combinations and timing of signal-sending and detection that determine which cells will take on which functions as the embryo develops its various organs, and as the organisms works their way through life. This is shown in Fig. 3. One combination for stem, another for leaf; one for brain, another for braincase: very different tissues, but the same genome. Symbolically in the figure, signals are represented as circles, triangles, or +'s. A cell expressing, say, a circle-receptor can detect the presence of circle-signals passing by, and when the receptor binds the signal the cell 'knows' about this event. If the cell does not present the receptor, as for ' + ' in the figure, it simply doesn't know the signal is out there, and cannot respond to it.

Life is all about cells, and cells are largely about signaling. As illustrated in Fig. 4, a cell is like the CIA headquarters: it 
Fig. 3 How signaling brings about change in cells. Top arbitrary combinations of signals are produced in some parts of a body or tissue; second row they diffuse across the tissue; third row where they are detected by cells expressing the appropriate (signal-specific) detectors; bottom row the detection of a particular combination of signals causes the cells to change their form or behavior. For more, see (Weiss and Buchanan 2009; Weiss et al. 2011)
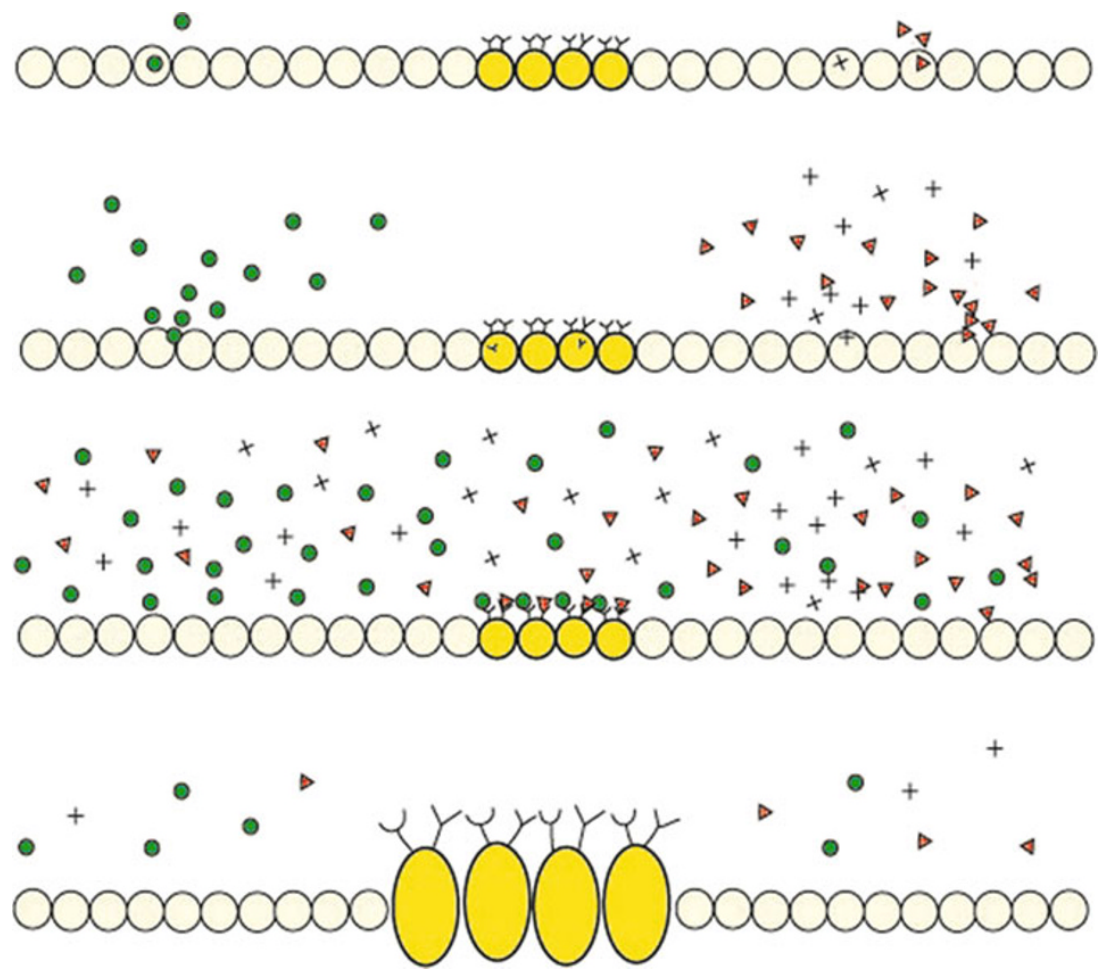

has all sorts of internal, partly self-sufficient departments, with communications among their various members (the intelligence agents), but it is largely sealed from the outside word - an ordinary citizen can't just wander in and roam around the place! At the same time, its roof is bristling with antennae, because its job is to monitor the world and respond to it. And it releases agents (signals) to pass information to allies elsewhere.

In the CIA, this is accomplished by electronics to detect signals and by agents exported to go out and pass information to other agents. In the cell, a partially sequestered internally structured environment, this information exchange is accomplished because the DNA in the inherited genome includes all the genes that code for all of the required proteins, including signal molecules, their signal receptors, and all the subsequent interacting molecules, including transcription factors that switch on other genes. Development and maintenance of the body during life are just the history of switching genes on and off, at each stage dependent on the signaling environment, which can include all sorts of signals from other cells, and from the broader environment that cells detect. Indeed, the same kinds of mechanisms are responsible for the interaction of members of a given species, or of individuals with their environment: light, odors, temperature, sounds, and so on are all used as signals for cells to detect and respond to.

Since our culture is in love with computers these days, we have a tendency to think of the information contained in genomes as a kind of self-contained computer program for the organism. But this is not the whole story, among other reasons because a program has a beginning and an end while an organism is a continuation of the cellular life of its parents. A fertilized egg can differentiate into an organism only because of the complex mix of proteins and other molecules that the egg contains along with its genome, and those ingredients determine which of the egg's genes will be used in its first stages, including signals being sent and received, so that subsequent stages can take place. Thus, your life was a beginning of you as an organism, but a continuation of the lives of both your parents - and their parents, and their parents, ad infinitum - all the way back to the origin of life itself-when we think that somehow spontaneous generation really did occur.

There are a couple of other important facts about how signaling allows our humble egg to turn into a sometimes not-so-humble adult. First, it is the combination rather than the physical properties of the sets of signals that causes cells to change. The signal is information, but its properties are not miniatures of what the cell will become. Referring metaphorically to Fig. 3, there is nothing "round" about the triangle signal that makes a cell become more round! Secondly, many if not most, signals are used in multiple parts of a developing body. This means that the combination is what we call functionally arbitrary. Again referring to the Figure, the "triangle" and "circle" signals (but in varying combinations) are used in multiple parts of the body. Thus, they comprise a limited repertoire of signals but produce an open-ended set of differing results.

In a nutshell: life is signaling. 
Fig. 4 The cell as an intelligence agency. A cell, loaded with localized internal departments with their respective sets of many interacting agents, closed to the environment (top), except for controlled passages and signal detectors littering its surface (a section of which is shown in the bottom panel). Figures by AV Buchanan. For details on this point of view as discussed by the author, and with reference to many other authors' work, see

(Buchanan et al. 2009; Weiss and Buchanan 2004, 2008, 2009; Weiss et al. 2011)

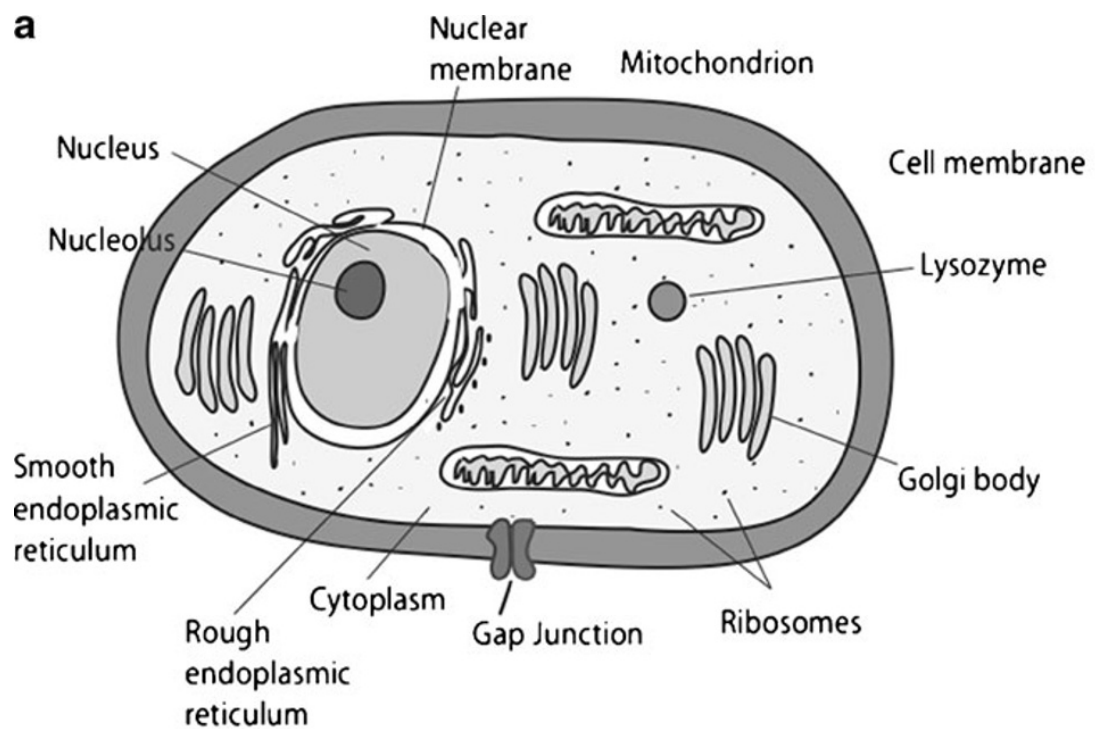

b

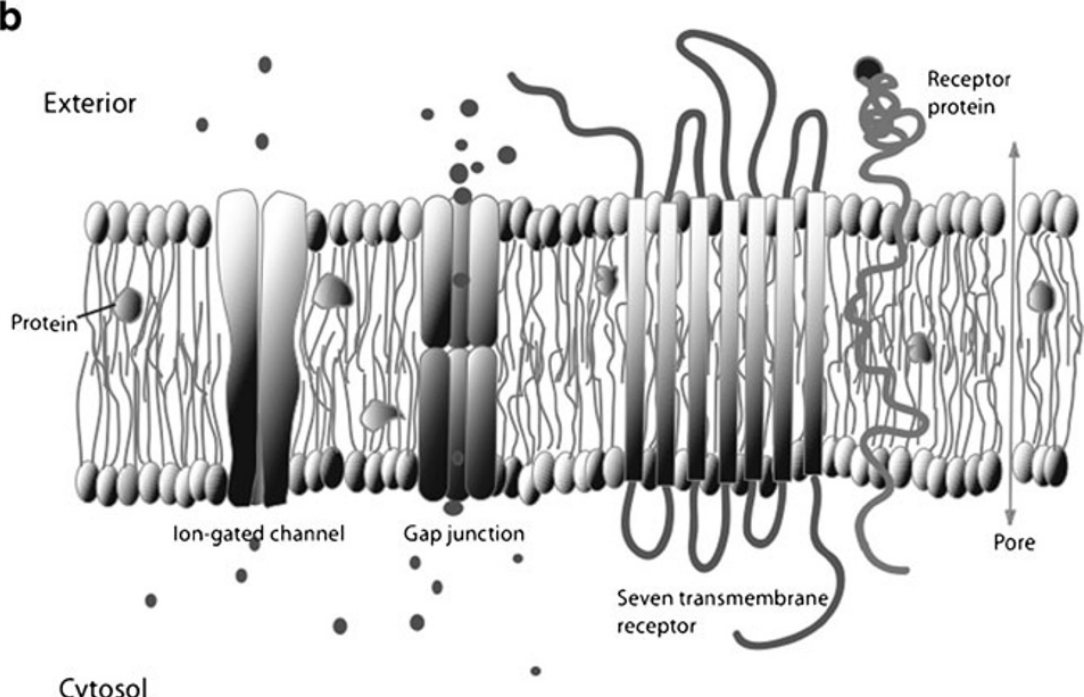

\section{How Signaling Makes You What You Are}

With these things in mind, one can now ask how various things we see in an organism come about (Weiss et al. 2011; Weiss 2005; Weiss and Buchanan 2008; Buchanan et al. 2009). Organisms are structured by many kinds of patterning that divide the individual into partly separated functional units or modules (cells, different organs and parts of organs), including symmetry (left, right), branching (lungs and vessels), repetitive structures (cells, hair, teeth, vertebrae, subunits of most organs like liver, kidney), segmentation (brain, sections along the intestines, limbs). This structural organization comes about through logically rather simple processes involving signaling.

From the fertilized egg on, cells typically have somewhat different makeup in different regions, often including one side anchored to some connective tissue or its sides tightly stitched by particular attachment structures to adjacent cells, plus a side that is open to the environment and where most of the signal molecules are found on the cell's surface.

So how do asymmetries such as left and right, front and back, top and bottom sides arise? If a cell splits into two, one descendant cell can become the forerunner of the left and the other of the right side of the body. After the split, barrier molecules can be secreted by each cell that separate it from its neighbor, so that each divides into a separate, isolated "tree" or branching of descendant cells into separate structures as the embryo develops. The barrier molecules are produced because at the time of their split, the cells had been stimulated - by various kinds of signaling - to produce them.

Each descendant limb - cell lineage - in this branching pattern is then instructed by its progenitor to express particular genes, secrete particular signals, and so on, cell generation after cell generation. The left side and right side may express similar sets of genes, but since they develop 
independently, the organism has, in essence, independent left and right sides that can be very similar, as ours are, without being aware of each other.

As cells divide, hierarchies of signaling can lead to differentiation, as for example first setting up a limb, then the divisions of the limb (upper and lower arm), then later structures (wrists and ankles, fingers and toes). It is the local signal environment that directs the immediate structures, and that environment can change along an axis, as cells stop secreting one kind of signal (or stop producing receptors to enable them to detect it), and start producing other signals. There are complex sets of these various signals that change over time and space.

Branching such as in plants or lungs can occur when cells produce signals that lead other cells in between them to undergo cell death and produce tissue barriers there instead. Then on each side of the barrier, as in left and right sides in the early embryo, lineages of cells can undergo similar differentiation to form a hierarchy of separate branches, lung lobes, and so on.

Once they begin to develop, most organs or organ systems in animals - and plants, too - consist of many repeats of the same structure. Leaves, petals, teeth, hair, and feathers are examples, but at the tissue level, similar patterning is typical. Some signals called "activators" trigger receiving cells to undergo differentiation by expressing genes that generate, say, a hair follicle. Other signals are produced, called "inhibitors," that signal neighboring cells to shut down or not to activate those cascades. But a few cells away, the inhibitor signal weakens and the activator signal takes over, initiating the cascade to produce a new follicle. Repetitive patterning may involve many genes, but in principle it is a nested cascade of signaling that gets used over and over again: you don't need a separate gene for each hair or tooth. Repetitive patterning is a basic way in which animals and plants generate their different organs and structures, and explains how they can become both so large and so complicated.

Once the commitment is made to generate a particular organ, such as a lung or limb, the cells no longer can be made to produce something else: they become committed to their fate. That is, even though they contain all the genes in the entire genome, they use neither the genes coding for the signals nor the receptors that would be needed to generate some other structure. This is possible because of isolation from cells committed to other fates. Again, the details may be complex, but the logic — the basic idea — is similar.

Attempts to induce cells in the laboratory to perform various functions that might be used to help people affected by particular diseases, such as replacement cells for people with sickle cell anemia or liver failure or damaged skin, use various types of relatively undifferentiated cells ("stem cells") to signal them to become the desired cell types. Thus, normal cells from the affected person can be first signaled to de-differentiate and then re-differentiate into the desired cell type. When such methods are perfected, there will be no danger that the person's body will reject the therapeutically implanted cells, because they are that person's own cells. Much success can be expected in the future from this new type of approach, because we have learned how signaling and gene expression determine cell type.

In such remarkable ways, organisms can be made of cells descended from a single cell, can all contain the same entire genome, and yet can form complex differentiated structures that make the sophisticated ways of life found on earth possible.

\section{How Information Evolved}

One might naturally ask how such an intricate system could have evolved out of the primordial "soup" in which the first life on earth seems to have arisen, about four billion years ago. No one really knows the early details, but we do have ideas about how things went once the DNA/RNA/proteincoding system got into place. Again the key is in the modular, flexible sequence nature of DNA.

As mentioned earlier, DNA can suffer mutations. The individual events are relatively rare in any given part of the genome, but from time to time nucleotides are changed - one substituted for another, or nucleotides mistakenly inserted into or deleted from the string one at a time or one chunk at a time. Mutations can change the amino acids that a gene codes for, and hence the nature of the coded protein, or they can change the way that transcription factors do (or don't) bind to a given regulatory region. Thus, mutations change gene function. It's how that function affects reproductive success which determines how or whether a change will proliferate in future generations.

Complexity requires the interaction of many different genes, and this raises the question of where these genes came from in the first place. The answer lies largely in types of mutation that involve the duplication of whole genes or chunks of DNA that contain genes. Such duplication events are rare, but they do happen at a low rate, and such an event can add a second copy of a gene, or part of a gene, that is transmitted to a child from what was present in the parent.

Once you have a second copy of a gene, it can accumulate mutational changes and take on a different function. Regulatory sequences can accumulate mutational changes so that the transcription factors that bind there no longer do so- so that the nearby gene is not expressed in cells that are also expressing the transcription factor gene. Or, the other way, a mutation may produce a new transcription factor binding site that will lead to genes being turned on in a type 
of cell where it wasn't before, leading the cells to be different.

Such changes by duplication and mutation will be screened by Nature to keep what works and remove what doesn't. Although it's a very, very slow process as a rule, the Earth is old, and over millions and millions of years, such changes occur. We have their signatures in genome DNA sequences, from which we can recognize genes that arose by duplication, and based on how different their sequence now is, we can estimate how long ago the duplication happened.

This highly structured use of genetically based information did not arise all at once. Instead, it evolved step by step over hundreds of millions of years. Early on, some rudiments of today's system were in place, and these were then elaborated in different descendant lineages into what we see today. In our own vertebrate lineage, some sort of primitive "fish" once existed that developed from a single fertilized egg through various embryological processes. That may have been the beginning of the vertebrate lineages, but it, of course, was already very sophisticated - in the ways we have been describing.

We can guess at what those early forms may have been like by comparing the embryos of today's living species (including humans) and seeing what features they share. There is a fine popular book on these subjects called Your Inner Fish (Shubin 2008), so long as you realize that the title (though not the book) is rather misleading. It seems to reflect what was once believed: that we have to go through evolutionarily earlier stages to get to our own later form, but that is not accurate. Nonetheless, there are striking resemblances between the early embryos of a fish, frog, fox, and you, that reveal the general nature of the way that signaling was elaborated over time, in different ways, diverging from some common starting points.

By comparing how embryos develop and what genes they use in the process, we can reconstruct the history of species and the organs of which they are made. We can trace the history of the skeletal system, the digestive organs, sensory and immune systems, and of course, the history of what we really mean by intelligence: the brain and nervous system. The whole picture is consistent: the consistent build-up of signaling hierarchies over time, from the single fertilized cell to the organisms, and from ancestral organisms to their descendant species. What we typically find is that today's basic organs systems have a billion or more years of traceable history. That's why, despite its marvelous complexity, biologists are completely convinced that life today is the result of this long, slow evolutionary process of genetically based divergence from common ancestry.

Once cells become committed to some kind of behavior, and are isolated from other cells in the embryo, they and their local environment can go off to some extent on their own (to some extent meaning that centrally sent signals like hormones, nutrients, a common body skin and shell, and so on, maintain the integrity of a single organism). Evolutionary events may have a tough time changing some of these early embryological commitments, but mutational changes and newly arisen genes can take new functions, typically that modify the basic body plan to add new structures or details. That is how oaks and maples have differentiated, as well as cats and cows.

In the senses we've considered here, life is a single phenomenon that one could say is an 'intelligent' informationexchanging phenomenon. If embryology is divergence of
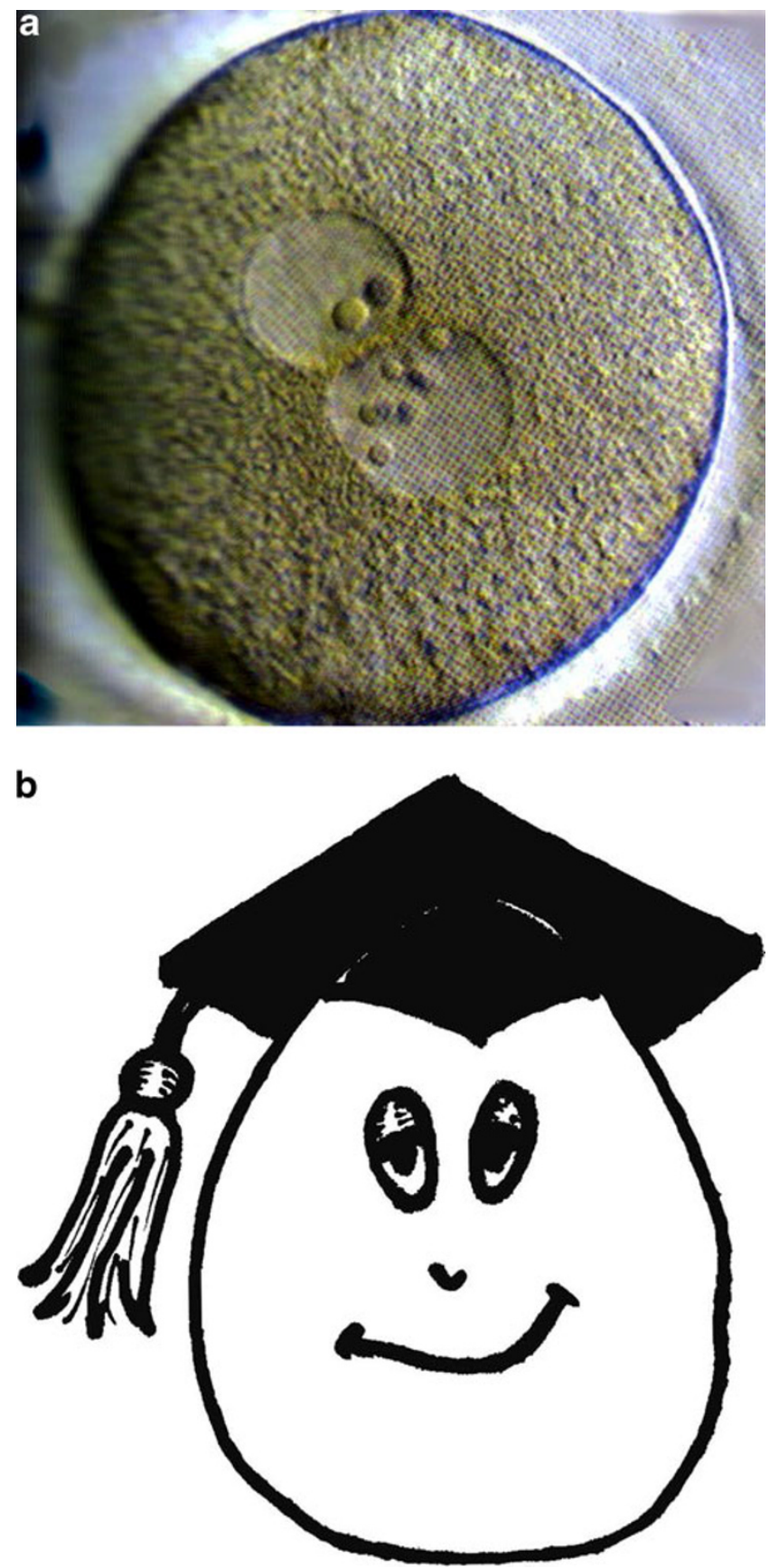

Fig. 5 An intelligent egg? a A fertilized human egg, can usually b graduate with honors. Sources: a Emory University Reproductive Center (Emoryhealthcare.org). b Drawing by the author 
information by differential usage of its genes in the tree of cellular descent from the single ancestral fertilized egg, then evolution is divergence of the information (genomes) among individuals in a tree of descent from a common ancestor. Among the related cells within an embryo, it is the usage of a given set of genes that differentiates the branches. Among related species, it is the set of genes that varies.

Thus information has been accumulating among different lineages of plant and animal life over evolutionary times, while information usage differences accumulate in different cell lineages within an individual lifetime.

In that sense, all of life is intelligent in the same way that an egg is.

\section{But the Egg Really Isn't Intelligent After All}

We like to personalize things in our imagination. One of the most difficult things to accept is that life may be based on "information," but that is a cultural word, while genes comprise an entirely impersonal system. Our conscious awareness and ability to manipulate things (including information in the computer sense) leads us to construct imagery of cells also using information in intentional ways. We often even speak as if this were a conscious activity, the cell doing what it "knows" to do. But of course, that is misleading because intelligent behavior need not involve consciousness (Fig. 5).

There is also a temptation to view the information contained in genomes as a "design" for the organism, but we must be careful with that imagery, too. There is built-in "design" in the sense that what happens during development is in an informational sense contained within the genome. But it wasn't built by design, and in particular, from a scientific point of view, life was not and is not constructed with any externally or internally derived endpoint in mind, or to "solve" problems presented by nature. Life just happens, mechanically. What results is the complex, if highly orderly, nature of the "information" contained within genomes, but even the word is misleading because genes are just molecules that interact with other molecules resulting in an organism. It is this orderly but impersonal nature of life that is perhaps most fascinating, even if it seems most contrary to our everyday notions and experience.

The egg may seem miraculous, and in ordinary terms it may be so. But it is a real, if cold, mechanism that can misfire, change, and is the starting point of an evolutionary dynamic that is what builds and maintains each of us. This deserves wonderment perhaps, but miracles have nothing to do with it.

The idea that life is all about signaling is somewhat different from the widespread view that Darwin's theory of evolution is at the core of life. Evolution is an important fact, which explains much about the variation we see now, and from the past, about life on Earth. Evolution is usually viewed, in a rather exaggerated way, as being all about competition. But life is much, much more about the interaction of cells and the information they exchange - that is, about cooperation - than it is about competition. Evolution helps specify the combinations that work in given times and places in life's history, but it is screening on successful cooperation more than on successful competition.

Each of us puts this genetic "intelligence" into cells we will contribute to our individual organs, and to the next generation. This intelligence develops and changes, but it doesn't get "better" in the usual human sense of progress, it can't be "educated," and it isn't "learned" (there is no Lamarckism as far as we know). That's the tough lesson of evolution and biology, at least as far as we currently understand it.

We fancy that we are very intelligent. We're the ones who write about plants and animals (and intelligence). But we have language, laboratories, libraries, and lecturers to learn from. Such knowledge comes from the outside. That's very impressive, but in fact it's made possible by the egg's enabling of the development of signaling and interconnections among our brain cells, and those connections are the basis by which we can absorb cultural knowledge and objects from our environment and interpret them to make sense of the world. Science is nothing compared to the achievements of the simple, intelligent egg.

Acknowledgments I thank Kat Willmore for inviting me to write this paper and Anne Buchanan for editorial suggestions. My relevant work is supported by the U.S. National Science Foundation, grant BCS 0725227, for which I am grateful.

\section{References}

Buchanan AV, Sholtis S, Richtsmeier J, Weiss KM. What are genes "for" or where are traits "from"? What is the question? BioEssays: news and reviews in molecular, cellular and developmental biology. 2009;31(2):198-208. doi:10.1002/bies.200800133.

Darwin C. The variation of animals and plants under domestication (orig. pub. 1868). New York: D. Appleton and company; 1900.

Hippocrates. On the sacred disease. Widely available in print and on the web; 450 BCE.

Shubin N. Your inner fish. New York: Pantheon; 2008.

Spallanzani L. Dissertations relative to the natural history of animals and vegetables. London: Murray; 1784.

Weiss KM. The phenogenetic logic of life. Nat Rev Genet. 2005;6 (1):36-45.

Weiss KM. The frog in taffeta pants. Evol Anthropol. 2004;12:5-10.

Weiss KM, Buchanan A. Genetics and the logic of evolution. Hoboken: Wiley-Liss; 2004.

Weiss KM, Buchanan AV. The mermaid's tale: four billion years of cooperation in the making of living things. Cambridge: Harvard University Press; 2009a.

Weiss KM, Buchanan AV. The cooperative genome: organisms as social contracts. Int J Dev Biol. 2009b;53:753-63.

Weiss KM, Buchanan AV, Lambert BW. The red queen and her king: cooperation at all levels of life. Am J Phys Anthropol. 2011;146 Suppl 53:3-18. doi:10.1002/ajpa.21608. 